\title{
Seasonal effect on semen availability and quality of racing pigeon in Thailand
}

Suwarak Wannaratana, Em-on Olanratmanee, Kuekaroon Charoenmuang, Thanvarath Boriharnthanawuth, Banpatee Tangtrongwanich, Thanawan Jongpattana, Yanita Sukhor, Arrita Kongthip and Thanida Sananmuang (D)

Faculty of Veterinary Medicine, Rajamangala University of Technology Tawan-Ok, Chonburi, Thailand.

Corresponding author: Thanida Sananmuang, e-mail: t.sananmuang@gmail.com

Co-authors: SW: suwarak_wa@rmutto.ac.th,EO: em-on_ol@rmutto.ac.th, KC: kuekaroon.cha@rmutto.ac.th, TB: thanvarath.bor@rmutto.ac.th, BT: banpatee.tan@rmutto.ac.th, T]: thanawan.jon@rmutto.ac.th,

YS: yanita.suk@rmutto.ac.th, AK: arita.kongthip@gmail.com

Received: 09-01-2021, Accepted: 22-04-2021, Published online: 07-06-2021

doi: www.doi.org/10.14202/vetworld.2021.1459-1464 How to cite this article: Wannaratana S, Olanratmanee E, Charoenmuang K, Boriharnthanawuth T, Tangtrongwanich B, Jongpattana T, Sukhor Y, Kongthip A, Sananmuang $T$ (2021) Seasonal effect on semen availability and quality of racing pigeon in Thailand, Veterinary World, 14(6): 1459-1464.

\begin{abstract}
Background and Aim: Seasonal variations among geographical regions could influence pigeon semen quality differently. This study aimed to determine the seasonal effect on semen availability and quality of racing pigeons in Thailand to understand and improve breeding management in the country.

Materials and Methods: Semen was collected from six fertile captive pigeons once a week during summer (March-June), monsoon (July-October), and winter (November-February) during 2019-2020. The success rate of semen collection and semen quality was determined in each season - by which changes in average temperature, humidity, and photoperiod were obtained.

Results: Comparable success rates of semen collection were acquired among different seasons, while varied semen qualities were revealed. The percentages of total motility and progressive motility score of sperm were significantly lowest in summer (66.35 \pm 3.40 and $3.88 \pm 0.15$, respectively) compared to monsoon $(85.45 \pm 2.91$ and $4.67 \pm 0.10$, respectively) and winter $\left(79.29 \pm 1.96\right.$ and $4.37 \pm 0.10$, respectively), while its concentration $\left(\times 10^{9} \mathrm{sperm} / \mathrm{mL}\right)$ and outputs $\left(\times 10^{6} \mathrm{sperm}\right)$ were significantly highest in winter (7.62 \pm 0.54 and $91.44 \pm 10.83$, respectively) compared to summer $(4.23 \pm 0.41$ and $48.45 \pm 6.35$, respectively) and monsoon ( $3.57 \pm 0.30$ and $51.45 \pm 7.21$, respectively). Besides, semen samples collected from birds housing at an average temperature of $<29.5^{\circ} \mathrm{C}$ demonstrated better sperm motility sperm concentration and total sperm counts than those from at a higher temperature.
\end{abstract}

Conclusion: Winter was regarded as the best season contributing the best semen quality, while summer was the worst. Due to the fluctuation of temperature during summer and winter, the seasonal temperature was implied as the major factor contributing to changes in sperm quality of racing pigeons in Thailand.

Keywords: humidity, photoperiod, pigeon semen quality, temperature, Thailand.

\section{Introduction}

Pigeon racing has been regarded as one of the most popular bird sports worldwide, including in Thailand $[1,2]$. To obtain pigeons with greater racing potentials, their breeding strategy is an important factor. Despite its annual breeding, only a few offspring of genetically exceptional pigeons is successfully bred. Striving to exploit genetic potential from such prestigious pigeons introduced assisted reproductive technologies (ARTs) in racing pigeons [3]. Among well-recognized ARTs, artificial insemination and semen cryopreservation are the most promising technologies in avian species [4]. To establish such technology, semen evaluation is a conventional tool

Copyright: Wannaratana, et al. Open Access. This article is distributed under the terms of the Creative Commons Attribution 4.0 International License (http://creativecommons.org/licenses/ by/4.0/), which permits unrestricted use, distribution, and reproduction in any medium, provided you give appropriate credit to the original author(s) and the source, provide a link to the Creative Commons license, and indicate if changes were made. The Creative Commons Public Domain Dedication waiver (http:// creativecommons.org/publicdomain/zero/1.0/) applies to the data made available in this article, unless otherwise stated. for monitoring the reproductive performance of male birds [5-8] and improving breeding strategy for racing purposes in pigeons $[9,10]$. Seasonal variation's effects on semen quality have been previously reported in several avian species, including pigeons [11-14]. Such influences were majorly contributed to temperature, and photoperiod varied among seasons. Interestingly, several studies even indicated varied seasonal effects among different geographic regions - which possess unique climate characteristics. It should also be noted that continuous climate change driven by human activities could also complicate the seasonal effect on semen quality. However, recent studies even manifested the influence of climate change on bird reproduction worldwide $[15,16]$. Alternative breeding performance of several avian species living in temperate zones has been reported, including changing breeding time, changing clutch size, the timing of nesting, reproductive success, and offspring sex ratios due to climatic change [17-20].

In temperate zone countries, such as Spain, the success rate of semen collection in amazons and 
macaws is highest in spring, while no semen collection is possible in autumn and winter [11]. On the contrary, pigeons in the Netherlands - which are located in a temperate zone but with a maritime climate, the success collection rate was highest in winter, while the highest volume was obtained in autumn [12]. Thus, these studies supported the contribution of geographical factors on semen availability and quality of the same climate zone. Thailand is a country located in a tropical zone. Seasons and climate of the tropical region are unique from those presented in the temperate zone - by which narrower ranges of temperature throughout seasons are common. The tropical region was well-recognized for its hot and humid climate, which contradicts those observed in the temperate zone. In several mammals and cocks in Thailand, the qualities of their semen were superior in the winter season [21-24]. Interestingly, Thai native cock seemed to be tolerated on fluctuated climatic changes among seasons [24]. Such acknowledgment implied the possible unique seasonal effect on semen characteristics of various species, including pigeons in Thailand.

Due to very limited knowledge about the seasonal effects on racing pigeons in Thailand, this study aimed to gain insight into the effect of seasonal variation on semen availability and quality acquired from racing pigeons. By acquiring data of climate parameters - temperature, humidity, and photoperiod, their effects on racing pigeon's semen in Thailand were first explored in this study.

\section{Materials and Methods}

\section{Ethical approval}

Experimental procedures were approved by Rajamangala University of Technology Tawan-Ok Animal Ethics Committee (RMUTTOACUC-2-2019-003), and care was taken to minimize the number of animals used.

\section{Study period and location}

This study was carried out from March 2019 to February 2020 at the Faculty of Veterinary Medicine, Rajamangala University of Technology Tawan-Ok in Chonburi province, the eastern part of Thailand.

\section{Animals}

A total number of six fertile racing adult male pigeons aged 1-2 years weighing 400-450 g were used. They were kept individually in metal cages and placed in the opened house exposed to natural environmental conditions. The birds were fed with $10 \mathrm{~g}$ of complete feed twice daily and water available ad libitum.

\section{Experimental design}

The semen was collected from six fertile captive pigeons once a week during summer (March-June), monsoon (July-October), and winter (NovemberFebruary) from 2019 to 2020 . The success rate of semen collection, semen quality, and meteorological data - average temperature, humidity, and photoperiod acquired among seasons was compared.

\section{Semen collection and evaluation}

Semen was collected from birds once a week by lumbosacral massaging and gentle squeezing at the base of the cloaca performed by the same collector throughout the study. The collected semen was diluted in LRS at 25-fold dilutions and was immediately evaluated for their quality [25]. The macroscopic evaluation included the determination of semen volume, $\mathrm{pH}$, and color. The microscopic evaluation included determination of total sperm motility, progressive sperm motility, sperm viability, sperm concentration, total sperm count, and sperm morphology.

\section{Semen volume and $\mathrm{pH}$}

The ejaculate volume was determined using a calibrated displacement pipette, while the $\mathrm{pH}$ was determined using $\mathrm{pH}$ indicator strips (Riedel-De-Haën AG, Germany). Each of the evaluation techniques was performed by the same evaluator for standardization.

\section{Sperm motility evaluation}

The percentage of total motile sperm and progressive motility was evaluated under a light microscope at $100 \times$ for 10 fields. Progressive motility of the sperm was graded on a 5-point score (0 indicates no motility, 1 indicates non-progressive motility, 2 indicates slow progressive motility, 3 indicates side to side movement accompanied by slow progressive motility, 4 indicates faster progressive motility, and 5 indicates very fast progressive motility) [3].

\section{Sperm viability and morphology evaluation}

Semen samples stained with eosin-nigrosin dye were assessed for sperm viability and morphology. The proportions of live (eosin-impermeable) and dead (eosin-permeable) sperm in a sample were assessed based on 200 sperm counts. For morphology evaluation, 300 sperm counts acquired from each sample were assessed for normal, amorphous head, bent head, macrocephalic head, acrosomal defect, loosed head, abnormal midpiece, proximal droplet, coiled tail, bent tail, distal droplet, loosed tail, and double tail sperms under a light microscope at $1000 \times$.

\section{Sperm concentration}

Sperm concentration was assessed by diluting $10 \mu \mathrm{L}$ of sperm suspension in $990 \mu \mathrm{L}$ of formal saline (100-fold dilution). The diluted sperm suspension was transferred to a counting chamber (Boeco, Germany) and the sperm concentration was then evaluated under a light microscope at $400 \times$.

\section{Meteorological data}

The data of average temperature $\left({ }^{\circ} \mathrm{C}\right)$, average humidity (\%), and average photoperiod (hours/day) were acquired from the Thai Astronomical Society and Thai Meteorological Department during 20192020. According to Thai Meteorological Department data, Chonburi Province was located at $13.22{ }^{\circ} \mathrm{N}$, $100.59^{\circ} \mathrm{E}$, classified as a tropical climate zone. All 
seasons were categorized as follows: (i) Summer: March-June; (ii) monsoon: July-October; and (iii) winter: November-February.

\section{Statistical analysis}

Normal distribution of the data $(p<0.05)$ was confirmed using the D'Agostino and Pearson omnibus normality test. Student's t-test was utilized to determine differences between two sample groups of interest, while one-way analysis of variance with Tukey's test for post hoc analysis was utilized to compare three sample groups $(\mathrm{p}<0.05)$.

\section{Results}

\section{Changes in temperature, humidity, and photoperiod} among seasons

Significant differences in average temperature, humidity, and photoperiod among the seasons were observed. Summer had the highest average temperature and longest photoperiod, while monsoon had the highest humidity compared to the others $(\mathrm{p}<0.05)$ (Table-1).

\section{Variation of semen availability and quality among seasons}

The acquired success rate of semen collection (approximately 80-95\%), semen volume

Table-1: Variables of average temperature, humidity, and photoperiod among seasons are expressed as mean \pm SE.

\begin{tabular}{lccc}
\hline Variables & \multicolumn{3}{c}{ Seasons } \\
\cline { 2 - 4 } & \multicolumn{1}{c}{ Summer } & Monsoon & Winter \\
\hline $\begin{array}{l}\text { Average } \\
\text { temperature }\left({ }^{\circ} \mathrm{C}\right)\end{array}$ & $30.70 \pm 0.11^{\mathrm{a}}$ & $29.42 \pm 0.11^{\mathrm{b}}$ & $28.47 \pm 0.14^{\mathrm{c}}$ \\
$\begin{array}{l}\text { Average } \\
\text { humidity }(\%)\end{array}$ & $72.98 \pm 0.45^{\mathrm{b}}$ & $78.13 \pm 0.55^{\mathrm{a}}$ & $68.39 \pm 0.74^{\mathrm{c}}$ \\
$\begin{array}{l}\text { Average } \\
\text { photoperiod } \\
\text { (hours/day) }\end{array}$ & $12.28 \pm 0.02^{\mathrm{a}}$ & $12.12 \pm 0.03^{\mathrm{b}}$ & $11.30 \pm 0.01^{\mathrm{c}}$ \\
\hline
\end{tabular}

Different superscripts within the same row indicated significant differences $(p<0.05) . S E=S t a n d a r d$ error (ranging between 10 and $13 \mu \mathrm{L}$ ), and sperm viability (approximately $84-86 \%$ ) was not different among the seasons. The $\mathrm{pH}$ of semen was lowest in summer $(p<0.05)$. Interestingly, marked decreases of total sperm motility and progressive sperm motility, along with marked increases of abnormal sperms (macrocephalic head, acrosomal defect, and abnormal midpiece), were manifested in summer $(p<0.05)$. On the contrary, sperm concentration and total sperm counts were highest in winter $(\mathrm{p}<0.05)$. Moreover, the percentage of normal sperm was significantly highest in monsoon than in the other seasons $(\mathrm{p}<0.05)$ (Table-2).

Effect of average temperature, humidity, and photoperiod on semen quality

Since environmental variables temperature, humidity, and photoperiod varied among seasons, their effects on semen quality were evaluated. Considering mean environmental variables 1 week before semen collection, semen samples collected from birds housing at an average temperature $<29.5^{\circ} \mathrm{C}$ demonstrated better sperm motility, sperm concentration, and total sperm counts than those acquired at a higher temperature. Average humidity greater than $72.5 \%$ and photoperiod longer than $12 \mathrm{~h}$ /day also contributed to decreases in sperm concentration and total sperm counts (Table-3).

\section{Discussion}

Unique seasonal effects on racing pigeon semen quality in Thailand were demonstrated in this study - by which the worst and best semen were obtained in summer and winter, accordingly. Supporting the notification about varied factors provided by different regional climates and environments, this study suggested winter as the optimal season for pigeon semen collection in Thailand - which was different from those previously reported in India [3] and the Netherlands [12].

Table-2: Semen quality compared among the seasons in Thailand. Data are expressed as mean $\pm \mathrm{SE}$.

\begin{tabular}{lccc}
\hline Parameters & Summer & Monsoon & Winter \\
\hline Total motility (\%) & $66.35 \pm 3.40^{\mathrm{b}}$ & $85.45 \pm 2.91^{\mathrm{a}}$ & $79.29 \pm 1.96^{\mathrm{a}}$ \\
Progressive motility (score $0-5)$ & $3.88 \pm 0.15^{\mathrm{b}}$ & $4.67 \pm 0.10^{\mathrm{a}}$ & $4.37 \pm 0.10^{\mathrm{a}}$ \\
Sperm concentration $\left(\times 10^{\%} / \mathrm{mL}\right)$ & $4.23 \pm 0.41^{\mathrm{b}}$ & $3.57 \pm 0.30^{\mathrm{b}}$ & $7.62 \pm 0.54^{\mathrm{a}}$ \\
Total sperm counts $\left(\times 10^{6}\right)$ & $48.45 \pm 6.35^{\mathrm{b}}$ & $51.45 \pm 7.21^{\mathrm{b}}$ & $91.44 \pm 10.83^{\mathrm{a}}$ \\
Morphologically normal sperm (\%) & $74.25 \pm 1.59^{\mathrm{b}}$ & $89.14 \pm 1.47^{\mathrm{a}}$ & $74.42 \pm 1.80^{\mathrm{b}}$ \\
Morphologically abnormal sperm (\%) & & $2.48 \pm 0.78^{\mathrm{a}}$ & $4.41 \pm 0.68^{\mathrm{a}}$ \\
Amorphous head (\%) & $4.75 \pm 0.68^{\mathrm{a}}$ & $1.96 \pm 0.28^{\mathrm{a}}$ & $2.99 \pm 0.35^{\mathrm{a}}$ \\
Bent head (\%) & $2.33 \pm 0.27^{\mathrm{a}}$ & $0.43 \pm 0.09^{\mathrm{b}}$ & $0.68 \pm 0.11^{\mathrm{b}}$ \\
Macrocephalic head (\%) & $1.64 \pm 0.15^{\mathrm{a}}$ & $0.55 \pm 0.14^{\mathrm{b}}$ & $1.20 \pm 0.24^{\mathrm{ab}}$ \\
Acrosomal defect (\%) & $1.62 \pm 0.23^{\mathrm{a}}$ & $1.53 \pm 0.34^{\mathrm{a}}$ & $0.33 \pm 0.11^{\mathrm{b}}$ \\
Loosed head (\%) & $1.76 \pm 0.28^{\mathrm{a}}$ & $0.35 \pm 0.21^{\mathrm{b}}$ & $0.84 \pm 0.20^{\mathrm{ab}}$ \\
Abnormal midpiece (\%) & $1.36 \pm 0.17^{\mathrm{a}}$ & $0.02 \pm 0.02^{\mathrm{a}}$ & $0.11 \pm 0.06^{\mathrm{a}}$ \\
Proximal droplet (\%) & $0.10 \pm 0.04^{\mathrm{a}}$ & $0.42 \pm 0.23^{\mathrm{a}}$ & $0.80 \pm 0.29^{\mathrm{a}}$ \\
Coiled tail (\%) & $0.54 \pm 0.15^{\mathrm{a}}$ & $0.16 \pm 0.06^{\mathrm{b}}$ & $4.63 \pm 0.94^{\mathrm{a}}$ \\
Bent tail (\%) & $5.64 \pm 1.01^{\mathrm{a}}$ & $0.01 \pm 0.01^{\mathrm{a}}$ & $0.05 \pm 0.03^{\mathrm{a}}$ \\
Distal droplet (\%) & $0.08 \pm 0.03^{\mathrm{a}}$ & $2.92 \pm 1.01^{\mathrm{b}}$ & $0.51 \pm 1.09^{\mathrm{a}}$ \\
Loosed tail (\%) & $5.89 \pm 0.85^{\mathrm{b}}$ & $0.02 \pm 0.02^{\mathrm{a}}$ \\
Double tail (\%) & $0.04 \pm 0.02^{\mathrm{a}}$ & & 0.02 \\
\hline
\end{tabular}

Different superscripts within the same row indicated significant difference $(p<0.05)$. SE=Standard error 
Table-3: Characteristics of pigeon semen categorized according to the average temperature, humidity, and photoperiod calculated at 1 week before semen collection. Data were expressed as mean $\pm \mathrm{SE}$.

\begin{tabular}{|c|c|c|c|c|c|c|}
\hline \multirow[t]{2}{*}{ Parameter } & \multicolumn{2}{|c|}{$\begin{array}{c}\text { Average temperature } \\
1 \text { week before semen } \\
\text { collection }\end{array}$} & \multicolumn{2}{|c|}{$\begin{array}{l}\text { Average humidity } 1 \text { week } \\
\text { before semen collection }\end{array}$} & \multicolumn{2}{|c|}{$\begin{array}{c}\text { Average photoperiod } \\
1 \text { week before semen } \\
\text { collection }\end{array}$} \\
\hline & $<29.5^{\circ} \mathrm{C}$ & $>29.5^{\circ} \mathrm{C}$ & $<72.5 \%$ & $>72.5 \%$ & $<12 \mathrm{~h}$ & $>12 h$ \\
\hline Total motility (\%) & $79.12 \pm 1.78^{a}$ & $70.90 \pm 3.46^{b}$ & $77.57 \pm 2.37$ & $74.08 \pm 2.55$ & $79.39 \pm 1.81$ & $71.86 \pm 3.09$ \\
\hline Progressive motility (score $0-5$ ) & $4.43 \pm 0.08^{a}$ & $4.03 \pm 0.15^{\mathrm{b}}$ & $4.27 \pm 0.12$ & $4.12 \pm 0.11$ & $4.42 \pm 0.09$ & $4.09 \pm 0.13$ \\
\hline Viability $(\%)$ & $87.49 \pm 0.70$ & $84.98 \pm 1.51$ & $87.92 \pm 0.84$ & $85.62 \pm 1.09$ & $87.99 \pm 0.73$ & $84.97 \pm 1.32$ \\
\hline Sperm concentration $\left(\times 10^{9} / \mathrm{mL}\right)$ & $6.62 \pm 0.47^{a}$ & $4.21 \pm 0.36^{b}$ & $7.60 \pm 0.63^{a}$ & $4.60 \pm 0.33^{b}$ & $7.38 \pm 0.50^{a}$ & $3.99 \pm 0.32^{b}$ \\
\hline Total sperm counts $\left(\times 10^{6}\right)$ & $78.89 \pm 8.72^{\mathrm{a}}$ & $52.59 \pm 6.04^{b}$ & $85.94 \pm 12.26^{a}$ & $58.25 \pm 5.71^{\mathrm{b}}$ & $87.89 \pm 9.83^{a}$ & $49.72 \pm 5.39^{b}$ \\
\hline
\end{tabular}

Different superscripts within the same row indicated significant difference $(p<0.05)$. SE=Standard error

In this study, the success rate of semen collection from racing pigeons was not significantly different among seasons (80-95\%). Such notification was different from those previously reported in the temperate zone - by which significant fluctuation of success rate varied through different seasons [12]. Seasonal effects on some semen characteristics acquired in this study were similar to those previously reported in India [3], which is located in the tropical zone like Thailand. Our result reported the highest semen volume during the monsoon season. As expected, such results contradicted those previously reported in the Netherlands - by which both semen volume and viability were greatest in autumn. The lowest percentages of total sperm motility and progressive motility, and the highest percentages of abnormal sperms during summer $(p<0.05)$ demonstrated in this study were also similar to those previously reported in India [3] and the Netherlands [12]. Even though most semen quality characteristics in this study were similar to those reported in India, sperm concentration and total sperm counts acquired from Thai pigeons were highest in winter $(\mathrm{p}<0.05)$, while the best results were presented during monsoon in India $(p<0.05)$ [3].

Although Thailand and India are both located in a tropical zone, this study strongly suggested that their differences in geographic influence could integrate with their climatic factors resulting in unique seasonal effects of each country. Different climate and environmental factors, such as ambient temperature, humidity, and photoperiod, were well-recognized for their variations among the seasons. During the time of this study, summer had the highest average temperature $\left(30.70 \pm 0.11^{\circ} \mathrm{C}\right)$ and longest photoperiod $(12.28 \pm 0.02 \mathrm{~h})$ than the other seasons $(\mathrm{p}<0.05)$. Monsoon had the highest average humidity $(78.13 \pm 0.55 \%)$ than the other seasons $(p<0.05)$. By evaluating changes in these climatic factors on semen quality, the results strongly implied the negative effects of high ambient temperature $\left(>29.5^{\circ} \mathrm{C}\right)$ on sperm motility, sperm concentration, and total sperm count $(\mathrm{p}<0.05)$. Moreover, sperm concentration and total sperm count were also negatively affected by high humidity $(>72.5 \%)$ and long photoperiod $(>12 \mathrm{~h} /$ day) $(p<0.05)$. Concordant with the seasonal effect's results, the increases of these climate factors were significant during summer seasons.

The effect of heat stress on decreasing sperm quality has been widely reported [26]. In a rooster, heat stress $\left(>30^{\circ} \mathrm{C}\right)$ compromises semen output, sperm viability, and motility $[27,28]$. Heat stress effect on sperm quality was also reported in pigeons - by which, sperm motility decreased at an ambient temperature greater than $28^{\circ} \mathrm{C}$ closed to $29.5^{\circ} \mathrm{C}$, as reported in the current study [12]. To the best of our knowledge, the negative effect of high humidity on sperm in Thailand was only reported in Duroc boar [21]. Our study was among the first reports that imply this negative effect on pigeons.

There is little information about the photoperiod effect on male reproductive performance in pigeons than other avian species. Optimal photoperiod was reported in turkeys $[29,30]$ and broiler breeder males [31,32]. In turkeys, the recommend photoperiod was 9.5-10.5 h/day [29]. In broiler breeders, the photoperiod of $>13 \mathrm{~h} /$ day contributes to decreased sperm concentration [31] and plasma testosterone concentration once broilers are exposed to long photoperiod 12-22 h/day [32]. These results suggested similar negative effects on other avian species. We also suspected these negative effects in racing pigeons used in this study; thus, further study is required to exclude all other interfering factors that might integrate their effects along with the photoperiod (especially the high ambient temperatures).

\section{Conclusion}

To the best of our knowledge, this study first demonstrates the seasonal effects on the semen quality of racing pigeons in Thailand. Winter was regarded as the best season contributing the best semen quality, while summer was the worst. Annual variation of temperature, humidity, and photoperiod was suggested to cause this contrast - by which hot weather was suspected the major factor that adversely affected the sperm quality.

\section{Authors' Contributions}

SW and TS: Planned the study design, analyzed data, and drafted the manuscript. EO, KC, TB, BT, 
TJ, YS, and AK: Performed semen collection and evaluation. All authors read and approved the final manuscript.

\section{Acknowledgments}

This study was funded by Agricultural Research Development Agency (Public Organization), Thailand under grant number CRP6205030260.

\section{Competing Interests} interests.

The authors declare that they have no competing

\section{Publisher's Note}

Veterinary World remains neutral with regard to jurisdictional claims in published institutional affiliation.

\section{References}

1. Scullion, F.T. and Scullion, M.G. (2010) Multiresistant Escherichia coli in racing pigeons. Vet. Rec., 167(22): 880-880.

2. Wannaratana, S., Thontiravong, A., Amonsin, A. and Pakpinyo, S. (2017) Persistence of Chlamydia psittaci in various temperatures and times. Avian Dis., 61(1): 40-45.

3. Sontakke, S.D., Umapathy, G., Sivaram, V., Kholkute, S.D. and Shivaji, S. (2004) Semen characteristics, cryopreservation, and successful artificial insemination in the Blue rock pigeon (Columba livia). Theriogenology, 62(1-2): 139-153.

4. Chowdhury, V.S., Sultana, H. and Furuse, M. (2014) International perspectives on impacts of reproductive technologies for world food production in Asia associated with poultry production. Adv. Exp. Med. Biol., 752: 229-237.

5. Neuman, S.L., Mcdaniel, C.D., Frank, L., Radu, J. and Hester, P.Y. (2002) Use of a sperm quality analyser on semen of turkey breeders to monitor storage time effects and age-related changes during a reproductive cycle. $\mathrm{Br}$. Poult. Sci., 43(3): 465-471.

6. Parker, H.M. and McDaniel, C.D. (2002) Selection of young broiler breeders for semen quality improves hatchability in an industry field trial. J. Appl. Poult. Res., 11(3): 250-259.

7. Parker, H.M. and McDaniel, C.D. (2003) Semen dilution prior to analysis influences the ability of the sperm quality analyzer to predict fertility whether inseminating with a constant number of sperm or a constant volume of semen. Poult. Sci., 82(11): 1808-1815.

8. Parker, H.M. and McDaniel, C.D. (2004) The optimum semen dilution for the sperm quality index that is most predictive of broiler breeder fertility. Int. J. Poult. Sci., 3(9): 588-592.

9. Klimowicz, M., Łukaszewicz, E. and Dubiel, A. (2005) Effect of collection frequency on quantitative and qualitative characteristics of pigeon (Columba livia) semen. $\mathrm{Br}$. Poult. Sci., 46(3): 361-365.

10. Klimowicz, M.D., Nizanski, W., Batkowski, F. and Savic, M.A. (2008) The comparison of assessment of pigeon semen motility and sperm concentration by conventional methods and the CASA system (HTM IVOS). Theriogenology, 70(1): 77-82.

11. Bublat, A., Fischer, D., Bruslund, S., Schneider, H., Meinecke-Tillmann, S., Wehrend, A. and Lierz, M. (2017) Seasonal and genera-specific variations in semen availability and semen characteristics in large parrots. Theriogenology, 91: 82-89.

12. Cheng, F.P., Guo, T.J., Wu, J.T., Lin, T.E., Ursem, P.J.F., Colenbrander, B. and Fung, H.P. (2002) Annual variation in semen characteristics of pigeons (Columba livia). Poult. Sci., 81(7): 1050-1056.

13. Frediani, M.H., Guida, F.J.V., Salgado, P.A.B., Gonçalves, D.R., Blank, M.H., Novaes, G.A. and Pereira, R.J.G. (2019) Semen collection by electro-stimulation in a variety of bird orders. Theriogenology, 125: 140-151.

14. Rakha, B.A., Ansari, M.S., Akhter, S. and Blesbois, E. (2017) Effect of season and age on Indian red jungle fowl (Gallus gallus murghi) semen characteristics: A 4-year retrospective study. Theriogenology, 99: 105-110.

15. Parmesan, C. and Yohe, G. (2003) A globally coherent fingerprint of climate change impacts across natural systems. Nature, 421(6918): 37-42.

16. Walther, G., Post, E., Convey, P., Menzel, A., Parmesank, C., Beebee, T.J.C., Fromentin, J., I, O.H. and Bairlein, F. (2002) Ecological response to recent climate change. Nature, 416(6879): 389-395.

17. Kwon, E., English, W.B., Weiser, E.L., Franks, S.E., Hodkinson, D.J., Lank, D.B. and Sandercock, B.K. (2018) Delayed egg-laying and shortened incubation duration of Arctic-breeding shorebirds coincide with climate cooling. Ecol. Evol., 8(2): 1339-1351.

18. Skagen, S.K. and Adams, A.A.Y. (2012) Weather effects on avian breeding performance and implications of climate change. Ecol. Appl., 22(4): 1131-1145.

19. Weatherhead, P.J. (2005) Effects of climate variation on timing of nesting, reproductive success, and offspring sex ratios of red-winged blackbirds. Oecologia, 144(1): 168-175.

20. Zuckerberg, B., Woods, A.M. and Porter, W.F. (2009) Poleward shifts in breeding bird distributions in New York State. Glob. Chang. Biol., 15(8): 1866-1883.

21. Suriyasomboon, A., Lundeheim, N., Kunavongkrit, A. and Einarsson, S. (2004) Effect of temperature and humidity on sperm production in Duroc boars under different housing systems in Thailand. Livest. Prod. Sci., 89(1): 19-31.

22. Koonjaenak, S., Chanatinart, V., Aiumlamai, S., Pinyopumimintr, T. and Rodriguez-Martinez, H. (2007) Seasonal variation in semen quality of swamp buffalo bulls (Bubalus bubalis) in Thailand. Asian J. Androl., 9(1): 92-101.

23. Nongbua, T., Utta, A., Am-In, N., Suwimonteerabutr, J., Johannisson, A. and Morrell, J.M. (2020) Effects of season and single layer centrifugation on bull sperm quality in Thailand. Asian-Australasian J. Anim. Sci., 33(9): 1411-1420.

24. Sonseeda, P., Vongpralub, T. and Laopaiboon, B. (2013) Effects of environmental factors, ages and breeds on semen characteristics in Thai indigenous chickens: A one-year study. Thai J. Vet. Med., 43(3): 347-352.

25. Sananmuang, T., Singto, T., Intarak, K., Sanansin, P., Budsasom, M., Kongthip, A. and Wannaratana, S. (2020) Optimizing system for sperm quality evaluation using crystalloid diluent for pigeons (Columba livia domestica). Thai J. Vet. Med., 50(2): 203-209.

26. Ashizawa, K., Wishart, G.J., Nakao, H., Okino, Y. and Tsuzuki, Y. (1994) Inhibition of temperature-dependent immobilization of fowl spermatozoa at body temperature by an increased intracellular pH. J. Reprod. Fertil., 101(3): 593-598.

27. McDaniel, C.D., Bramwell, R.K., Wilson, J.L. and Howarth, B. (1995) Fertility of male and female broiler breeders following exposure to elevated ambient temperatures. Poult. Sci., 74(6): 1029-1038.

28. Mcdaniel, C.D., Bramwell, R.K. and Howarth, B. (1996) The male contribution to broiler breeder heat-induced infertility as determined by sperm-egg penetration and sperm storage within the Hen's oviduct. Poult. Sci., 75(12): 1546-1554

29. Noirault, J., Brillard, J.P. and Bakst, M.R. (2006) Effect of various photoperiods on testicular weight, weekly sperm 
output and plasma levels of LH and testosterone over the reproductive season in male turkeys. Theriogenology, 66(4): 851-859.

30. Yang, J., Long, D.W., Inpanbutr, N. and Bacon, W.L. (1998) Effects of photoperiod and age on secretory patterns of luteinizing hormone and testosterone and semen production in male domestic turkeys. Biol. Reprod., 59(5): 1171-1179.
31. Floyd, M.H. and Tyler, N.C. (2011) Photostimulation of male broiler breeders to different photoperiods. S. Afr. J. Anim. Sci., 41(2): 146-155.

32. Tyler, N.C., Lewis, P.D. and Gous, R.M. (2011) Reproductive status in broiler breeder males is minimally affected by a mid-cycle increase in photoperiod. Br. Poult. Sci., 52(1): 140-145.

$* * * * * * * *$ 